\title{
Mexico and China-Sustainable, Low-Carbon Transformation Processes in Democratic and Authoritarian Regimes
}

Mexico and China are two dynamic countries that can 'challenge' existing normative views on regimes, governance, and institutions. On the one hand, Mexico is a vibrant democratic country that has managed to become a member of the OECD and its economy has benefitted from open borders, direct foreign investment inflows and integration into global value chains (OECD 2017b), but yet it still reflects governance deficiencies, particularly in the formal and material representation of relevant stakeholders, and especially in marginalized communities. On the other hand, although China is governed by an authoritarian regime, particularly when environmental issues are involved, societal groups' interests seem to find effective ways to influence policy-making. In addition, as the Chinese government has discovered the opportunities of integration into global value chains, moving into higher value-added production by improving the quality and relevance of innovation (OECD 2017a), it is able to achieve the approval of its domestic audience, which further consolidates the standing of the Communist regime.

Strategically, the Chinese regime was able to 'link' this 'upskilling' policy goal with climate protection and sustainable developmental goals, paving the way for the achievement of 'moral power', both domestically and internationally, and eventually assume global leadership. With certain European countries currently confronted with financial crisis, austerity measures, and legitimacy gaps, a vacuum has emerged, which may derail the climate negotiation process. Such a leadership in China will most likely require focusing on a partnership with urban clusters or networks of cities (chengshiqun), local societal groups, business and investment groups aiming to advance environmental integrity, sustainable development and energy security. As it becomes apparent that global leadership is becoming a key aspect of Chinese foreign policy, China has increasingly moved 
into either creating new platforms for global and regional partnerships of development such as the Belt and Road as well as the Beijing-Hebei-Tianjin Corridor, or reconfiguring the rules of existing international institutions by assuming different types of leadership. Nevertheless, as Thomas Hale (2017) highlights, China still needs to find new avenues for climate leadership that cater to non-traditional channels of diplomatic influence.

Mexico and China are very seldom compared. In this chapter, the Mexico-China comparative case study suggests each are using the other as the 'alternative setting.' Particularly in the context of sustainable, low-carbon transformation, such a comparative approach can provide interesting insights, especially when 'normative traps' become evident. For example, the short-comings of democratic regimes and the advantages of authoritarian regimes in policy implementation are often downplayed, because the success of policy implementation tends to be merely defined by input legitimacy. However, an important requirement for such a comparison is to initially put aside, at least for analytical purposes, the normative lens of democratic and authoritarian regimes. Here, context beats the purported logic of policy models. This should not, however, be taken as an argument supporting authoritarian regimes. Understanding how authoritarian regimes are able to effectively address specific problem issues of low-carbon transformation can contribute useful knowledge to democratic regimes and vice-versa.

\section{Hypotheses: Identifying New Variables and New Interdependencies}

Any system transformation is highly contextual. Therefore, as argued in Chapter 7 , each case study will most likely lead to the identification of new variables and interdependencies or re-discovering old variables that assume new meanings or significance, which can be later conceptualized. This approach aims to instigate further theory development.

The following hypotheses intend to highlight the overlaps and deviations between the ideal types (chapter 8) and the case studies on China and Mexico.

Hypothesis 1: The successful implementation of sustainable, low-carbon policies is highly contingent on the capacity and autonomy of the state.

Relevant questions include: are democratic regimes more effective than authoritarian regimes in achieving sustainable, low-carbon developmental policy goals (policy formulation, coordination, implementation, verification and 
modification)? Are hybrid regimes the solution? If yes, which elements of both governance models should be selected when designing the regime?

Hypothesis 2: Both democratic and authoritarian regimes can manage transformation processes.

Paradoxically, participative bargaining interactions do not exclusive occur, nor are they guaranteed in democratic countries. By understanding how institutional, functional and bargaining interactions can be planned and executed, both democratic or authoritarian regimes can establish effective transformation management.

Hypothesis 3: The historicity of transformation processes implies that decisions or policies are to be designed and implemented case-by-case or point-by-point.

As such, analytical methods that allow the analysis of scales, episodes and subsystems are needed. Ideal type analysis suggests additional subjects and additional ways of analyzing historical, social processes for further research, allowing a more integrated approach to problems and solutions.

Hypothesis 4: The effective management of transformation processes requires 'negotiative' mechanisms that allow continuous the revisiting of decisions made.

By focusing on various negotiation episodes, levels, or stages, the resilience of transformation processes can be ensured. Through this, distinct conditions of each episode, level or stage can be highlighted, allowing retrofitted solutions.

\subsection{Context-Transformation Processes and Governance Models}

The evaluation of the state of sustainable, low-carbon transformation in Mexico and China entails a participatory approach through which the different levels and scales of the 'involvement' of relevant stakeholders will be highlighted. 


\subsubsection{The Paris Agreement and Responses from Mexico and China}

\subsubsection{Mexico}

Ahead of the UNFCCC COP meeting in Paris in December 2015, Mexico had already ratified the agreement in March 2015. Mexico was also the first developing country to submit a climate pledge to the 2015 COP meeting. By doing so, the Mexican government had officially committed to meet its climate goals by upscaling its 'Intended Nationally Determined Contribution' (INDC) from mere intentions to formal policy goals (see Secretaría de Relaciones Exteriores 2017). Mexico understands itself as a major climate champion while its government aims to achieve the following:

- Unconditionally reducing GHG emissions by 22 percent and black carbon by 51 percent of business-as-usual levels by 2030 . With assistance, the government aims to increase these reductions by 36 percent (GHG) and 70 percent (black carbon).

- Conditionally reducing GHG and black carbon emissions (35 percent and 70 percent respectively), contingent on international support.

- Achieving peak net emissions from 2026 and reducing emissions per unit of GDP by around 40 percent from 2013 to 2030.

- Reducing emission intensity per unit of GDP by 40 percent between 2013 and 2030.

- Committing to various adaptation measures to lessen the vulnerability of local communities to climate change and to ameliorate climate impacts on ecosystems, infrastructure and productive systems. In addition, the Mexican government commits to achieving zero percent deforestation by 2030 .

To achieve these goals, Mexico introduced a major new policy on clean energy through the 'Energy Transition Law'. With the energy sector responsible for 70.8 percent of Mexico's GHG emissions (Climate Links 2017), this new policy envisions generating at least 25 percent of its electricity through clean energy by 2018, 30 percent by 2021, and 35 percent by 2024. Nevertheless, even though many of new reforms in Mexico call for sustainable development and climate protection, many policies still favor the fossil fuels sector. In 2015, petroleum and natural gas accounted for most of Mexico's total fuel consumption for transportation and electricity generation, at 45 percent and 40 percent respectively (EIA 2016a). This is because the energy sector (electricity and hydrocarbons) is generally open to private investment, which tend to favor the exploration and 
exploitation of shale gas as a key goal. Therefore, as the Special Program of Climate Change of the Mexican government (PECC) recognizes, energy reform and the exploitation of shale gas in Mexico could actually lead to an increase in greenhouse gas emissions, which means that the reform would actually go against the national climate commitment (Energy Transition 2014).

In addition, the Energy Transition Law still needs to be complemented by additional knowledge of the impacts of targets that are yet to be quantified. Furthermore, because this law assumes a definition of clean energy that includes co-generation, which means natural gas- $\mathrm{a} \mathrm{CO} 2$ emitting source of energy-will be playing a crucial role, doubts among the scientific community have emerged (Climate Action Tracker 2017b). The consumption of natural gas now accounts for 23.6\% of fossil-fuel CO2 emissions (see Boden et al. 2017; CDIAC 2017). For example, this could mean that the emissions will be 6 percent higher in 2030 and that the share of renewables in 2024 will be merely 29 percent. Therefore, Mexico will need to commit to additional policies in order to reach its NDC target.

\subsubsection{China}

China ratified the Paris Agreement on September 3, 2016. The Chinese government has identified and centered its policies on reaching its NDC goals. Some important elements of its NDC include:

- Peak CO2 emissions by 2030, or earlier if possible;

- The reduction of the carbon intensity of its GDP by 60 to 65 percent below 2005 levels by 2030

- An increase of the share of non-fossil energy sources in the total primary energy supply to around 20 percent by 2030

- An Increase of the forest stock volume by around 4.5 billion cubic meters (40 million hectares of forest coverage) by 2020 compared to 2005 levels

Nevertheless, while the policies and intended actions of the Chinese government could be adequate to enable China to overachieve its NDC as well as its national targets, the Chinese NDC is seen as not ambitious enough to be consistent with holding warming to below $2{ }^{\circ} \mathrm{C}$ as required under the Paris Agreement, and is instead consistent with warming between $3{ }^{\circ} \mathrm{C}$ and $4{ }^{\circ} \mathrm{C}$ (Climate Action Tracker 2017a). However, while China is currently the biggest source of $\mathrm{CO} 2$ emissions with around 30 percent, followed by the United States with 15 percent (Boden et al. 2017), it cannot be blamed alone for this failure to achieve the global $2{ }^{\circ} \mathrm{C}$ target. China's emissions are merely half of U.S. emissions on a per capita basis. 
In addition, most of China's emissions are attributed to manufactured goods exported to the United States and other European countries. Moreover, based on historical $\mathrm{CO} 2$ emissions, U.S. climate-damage responsibility is twice as much of that of China, even without normalizing for population. Most importantly, China's emissions have been stabilized and have now been constant over the last three years (Carbon Tax Center 2017).

When the 18th National Congress of the Communist Party of China initiated the concept of 'eco-civilization' as a new model of the modernization of harmonious human-nature development, it sets the new framework for present and future strategies on planning to conform to the world trend. China has already built the world's biggest installed capacity of wind and solar power, and its climate policies are embedded in its current five-year economic plan. With China's slowing economic growth, the Chinese government has identified the potentials of expanding its dominance in low-carbon technologies, which can serve as the engine of the next phase of its economic growth. In 2016, China invested USD 102.9 billion in renewable energy and installed half of the world's new wind power, as its coal consumption has peaked and has begun to decline.

\subsubsection{Multiple Entry Points to Climate Mitigation in Mexico and China}

Entry points can be understood as problem-issues related to other policy priorities such as sustainable development and energy security, whose resolution can be coupled with climate mitigation, that is, with emission reduction through renewables or through energy efficiency technologies. By focusing on synergies and co-benefits, policy-makers might find it easier to push for more ambitious climate protection policies. Sustainable development goals can be coupled with climate protection goals particularly after trade-offs between these policy goals and policy implementation measures can be identified and managed.

The entry points that will be discussed below do not comprise a complete list of all entry points to climate mitigation in Mexico and China. This selection intends to highlight the most relevant as underscored by the theoretical models (ideal types).

\subsubsection{Mexico}

There are various entry points to climate mitigation for Mexico. A potential entry point to climate mitigation for the Mexican government is its political priority of addressing the social and economic impacts of migration to the country. As 
extreme weather events cause economic damage, climate change increases the probability that Mexicans migrate to the United States and from rural to urban areas within Mexico (see Jessoe et al. 2016). The effects of climate change, such as water scarcity, diseases, food scarcity and rising sea levels, induce the increasing rates of internal and external migration, which are becoming more of an economic and political concern in terms of both the origins and the destinations (see Nawrotzki et al. 2015), climate mitigation needs to be a central element of any policy that aims to address migration. Nevertheless, as the effects of Mexico's climate mitigation efforts cannot be easily converted to concrete outcomes in the affected areas (e.g., observable resolution of water scarcity), Mexico's climate mitigation efforts need to be accompanied by short-term successes in terms of containing migration.

One example of such coupling of climate mitigation and addressing migration is to ensure local community development, particularly in areas where renewable energies such as wind, geothermal and solar are developed and expanded. Renewable energy projects in rural areas should be reliable sources of both highand low-skilled jobs. The promotion of intelligent growth in rural Mexico, for example through geothermal energy, needs to be driven by innovation and by the expansion of value chains in the context of community development, gender equality, empowerment of indigenous communities, social innovation, youth empowerment and innovative entrepreneurship. Furthermore, renewable projects in rural areas need to be accompanied by the development of local infrastructure and expertise in order to build new capacities while reversing emigration. A huge challenge for various renewable projects (e.g., Mareñas Renovables in Oaxaca) is to address the situation that most workers in such areas are fishermen or farmers who will most likely be negatively affected by such projects (e.g., noise, water and air pollution leading to less catches or less agricultural yields). Therefore, the creation of knowledge-intensive sectors and services needs to be equally beneficial for other sectors (e.g., agriculture).

The sustainability of economic development processes based on the utilization of renewable energies in Mexico depends not only the Large and Multinational Companies (MNEs), but to a large extent on the incorporation of local traditional partners in this process - the Small and Medium-Sized Enterprises (SMEs). Climate mitigation projects need to initiate not only national and regional, but also local value creation by fostering the role of renewable energy and energy efficiency technologies in creating new market opportunities and the promotion of technology-based entrepreneurship with a focus on SMEs.

To avoid the traps of natural resource abundancy (the 'resource curse', or the 'paradox of plenty'), local economic development strategies need to utilize the 
energy project as an entry point to support new knowledge-intensive businesses, thereby upgrading the local economy in terms of capabilities and knowledge. Its focus is on the development of Technology-Intensive Suppliers (TIS), characterized by skilled activities such as manufacturing specialized machinery \& production inputs and knowledge-intensive services. For instance, the utilization of geothermal energy in Mexico can open diverse new opportunities as well as challenges for SMEs, as specialized supplies and expertise in automation, precision, and scientific instruments, among others, are needed. Supporting the local supply of these goods and services avoids development in the form of enclaves, which export much of the production and import key inputs, capital goods and specialized services. In order to support this process, the project will actively promote, guide, and sustain the development of competitive new business models arising out of the energy project.

Another point of entry to climate mitigation in Mexico is the promotion of social cohesion by recognizing the importance of integrating societal groups into the value chain, preventing future conflicts that could delay mitigation projects. Social cohesion, or the lack thereof, has been a huge deficit in Mexico's democratic system, where the political elite has often pursued a top-down approach in policy-making, resulting in civil society groups concentrating more on governance issues rather than other important issues such as environmental protection and sustainable development. The participation of civil society groups can not only ensure a high level of public acceptance of renewable energies and the elimination of caveats against behavioral change, it can also promote evidence-based debates, which can further contribute to the maturity of technologies. Understanding the social ramifications of renewable energy technologies can help improve these technologies.

In addition, promoting gender equality can be a significant entry point to climate mitigation. The studies and investigations on gender elaborate upon the perspective of gender in analyzing how organizations and society produce inequalities through social positioning based on gender. Gender inequality is therefore an indicator of structures that produce various types of imbalances. Addressing and correcting gender inequality will most likely produce synergies and co-benefits that will resolve other types of imbalances. Masculinity and femininity are understood as cultural and social constructs through which society is organized and through which symbolical differences are defined. The category 'gender' fulfils the function of manifesting mechanisms and dispositions which create and reproduce spaces for the subordination, discrimination and marginalization of women in societies (see Kreisky 1979; 2008). The rationale for addressing the issue of gender equality and gender mainstreaming in research 
and innovation revolves around the principles of non-discrimination and equality, efficiency and competitiveness, preventing the waste the talent and potential contributions of highly educated women, increasing innovation potential and ensuring the conduct of socially responsible and accountable research and innovation through the integration of sex/gender analysis. Furthermore, integration of the gender dimension creates new ideas and opportunities for innovation. Thus, gender diversity and the consideration of the gender dimension in research content has a direct effect on improving scientific quality, social responsibility, and the robustness of research and innovation.

\subsubsection{China}

China has numerous entry points to climate mitigation. A major entry point to climate mitigation refers to China's efforts to sustain and enhance its global economic competitiveness, which legitimizes the current political regime. The Chinese government understood that from the examples of South Korea and Japan, its next phase of economic development involves a significant upgrade in its capacity to produce advanced and higher-value technologies, where China is able to own intellectual property rights. In addition, while there is still some resistance to its low-carbon energy transformation, traditional energy companies in China have fewer political resources to obstruct low-carbon policies. As such, these companies often pursue a pragmatic approach by cooperating with authorities and supporting policies that pose constraints to their own business interests. This is another entry point to climate mitigation in China, where the political system limits dissent and fosters a political culture where authorities are 'trusted.' Whether this trust is based on decades of propaganda through state controlled media, on collective narratives about the 'incorruptible' leaders (Hsu 2001), or on the persecution of dissenting voices is at this point a subject of a separate debate.

After a political crisis in the 1980s where intellectuals were able to draw upon the traditionalist collective narrative of corruption to blame the communist leadership for social problems, the Chinese government and the state-controlled media revised the narratives of corruption. In the 1990s, the role of the state was then no longer understood as a moral or ideological leader, but as that of an economic manager. As Hsu (2001) argues, Chinese leadership managed not only to control the corruption crisis, but it also found an effective channel for ensuring political legitimacy through the narrative "economic prosperity." With the slowing economic growth in China, the leadership has become more open to new policies that could sustain the very economic growth that legitimizes the current political order. 
Another major entry point for climate mitigation is the coupling of emission reduction with the recognition of the social, economic and health impacts of environmental degradation, especially of air pollution (see Cao 2018; Trombetta 2019). Finally, shortly before and during the Beijing Olympic games, the Chinese leadership recognized the environmental effects of three decades of an economic growth that builds on high-carbon energy technologies. The social, economic and health impacts of air pollution in major cities, the loss of biodiversity, the water crisis, and soil contamination have created a sense of political urgency. These impacts of environmental degradation, as well as the impacts of climate change (extreme weather events and floods) are seen as threats to economic well-being. This urgency has opened another entry point for climate mitigation, paving way for the Xi Jinping administration (2013 to present) to adopt "ecological civilization" as a political vision. This vision was translated into actions including the restoration of decimated forests, efforts to stop the expansion of the Gobi Desert, the promotion of electric mobility, and eco-friendly urbanization. The most recent plan to realize this vision is the $4,500 \mathrm{~km}$ long 'Green Wall of China' or the 'Three-North-Shelterbelt Program' which is a huge ring of newly planted forests. This program, which was conceptualized as early as 2001, is planned to be completed by 2050 and aims to stabilize the soil, retain moisture and act as a buffer against further desertification (see BBC News 2001; Petri 2017).

\subsection{Case Study: The Agency of Transformation Process in Mexico-Gaps in the Discursive Function of Governance}

Some of the main challenges and barriers to Mexico's low-carbon transformation are defined by the dilemma of the self-fulfilling prophecy, whereas Mexico's current efforts, which are already perceived by Mexico as highly ambitious, are assessed as not enough to allow the country to achieve its NDC. This dilemma can be categorized as a structural barrier, as it limits the set of possible future actions. Particularly because Mexico's targets as concretized by its NDC are not consistent with limiting warming to below $2{ }^{\circ} \mathrm{C}$, let alone with the Paris Agreement's stronger $1.5^{\circ} \mathrm{C}$ limit, additional perspectives are needed. The Climate Action Tracker evaluates Mexico's current pledges. While Mexico has pledged to reduce its GHG emissions by 22 percent below baseline in 2030, equivalent to an increase of emissions by 56 percent above 1990 levels, the long-term pathway (red dashed lines) from 2030 to 2050 is simply, according to current knowledge, not attainable. Therefore, there is a need to conceptualize strategies that can 
be isolated from the anchors set by the knowledge that Mexico's efforts are not enough to attain the $2{ }^{\circ} \mathrm{C}$ goal.

Another challenge for Mexico's low-carbon transformation is to increase the clarity of strategies for reducing emissions in key sectors, particularly electricity and transportation. There is consensus in the policy, polity and politics sides that Mexico has the potential to move rapidly towards a low carbon future (ESMAP 2016). Although Mexico is a significant oil producer, it seeks to develop its vast potentials on renewable energies including geothermal, bioenergy, solar, and wind, because of steadily decreasing oil production since 2005. Nevertheless, Mexico still has a long way to go before it can depart from its dependence on fossil fuels, which constituted a total of 93 percent of the total energy consumption in 2015 (EIA 2016b).

With this background, low-carbon transformation in the country will require scenarios that provide fossil fuels with a bridging role to assure a bearable transition. New constitutional and policy reforms were already introduced by the government to promote transition, through diversification of the energy portfolio including tax reform, the liberalization of electricity supply, and ending the monopoly of the state-owned Petroleós Mexicanos (PEMEX). However, the volatility of world oil prices inhibits clear decisions, as the government might reverse some of its reforms when oil prices increase. Therefore, new arguments aside from low oil prices should be found as to why the development of renewable energies should be further expanded.

The current efforts of the government to achieve low-carbon economic development are defined by the country's national development policy as outlined in the "Estrategia Nacional de Cambio Climático-Visión 10-20-40" (National Climate Change Strategy) (SEMARNAT 2013). The national strategy is based on a study that encompasses various scenarios of emission reduction. The World Bank, in collaboration with the Energy Sector Management Assistance Program (ESMAP), conducted the study "Mexico-Estudio Sobre la Dismínución de Emisiones de Carbon" for the Mexican government. The study assesses the potential for GHG reduction in Mexico in the next few decades. The main objective of the national strategy is to allow the country to significantly reduce it GHG emissions without hindering economic growth (ESMAP 2016). This principle mainly defines the tolerable window for Mexico's low-carbon economic development. Present and future decisions are required to follow this principle.

Based on this national strategy of the government, five principal sectors have been identified, indirectly identifying the different actors that need to be part of the negotiations-electric power (e.g., electricity utilities, transmission line providers), oil and gas (e.g., oil importers and suppliers, refineries, distributors), 
energy end-use (e.g. manufacturing and construction industries, residential, commercial and public sectors), transport (e.g., road transportation companies), and agriculture and forestry (e.g., crop and timer producers, forest land managers and biomass energy producers). Aside from the evident actors, societal groups, including indigenous communities, the urban poor, farmers and fishers, will want to participate in all decision-making processes, as their livelihood, culture, and self-determination will be affected by any changes made in these five sectors. The concrete roles of these actors are, however, not explicitly discussed in government policy papers. In addition, there is no clear reference to formal procedures that would allow stakeholders to be fully integrated into the formal decision-making process.

Low-carbon transformation in Mexico requires 'strong' and strategic policies. However, it is argued by this book that Mexico needs to complement these ambitious energy, climate protection, and sustainable policies with reforms of its governance system, particularly how state institutions should function as a nexus of social integration. As it will be discussed in this section, democratic structures in Mexico further conflate various conflicts, with challenges to climate protection merging with governance issues, further increasing the complexity of low-carbon transformation. As many conflict cases involving renewable energy projects in Mexico suggest (e.g., wind power in Oaxaca), it will most likely make no difference whether Mexico will be successful in designing policies that will make it achieve its NDC or not, as in both cases these policies will lack legitimacy, as they often do not carry social acceptance, particularly in local communities. Without this social acceptance, the ambitious climate protection policies of the central government will be initially framed and defined as intrusion.

\subsubsection{Analysis between the Ideal Type and the Empirical Case Study of Mexico-Causal Mechanisms through Congruence Methods and Process-Tracing}

Chapter 8 has introduced the democratic policy pathway as an ideal type of transformation. The following are the most relevant provisions of this ideal type in the context of transformation towards sustainability:

- The competitive advantage of political actors in democratic countries is defined by how it can manage to align their political interests with public opinion or how these political actors can shape public opinion. 
- Universities and other academic institutions play a significant role in providing 'public space' where various societal groups can meet and exchange perspectives.

- Consensus-building mechanisms have the purpose of defining consensual knowledge.

- The government agenda on low-carbon transformation is significantly defined by the ideological preferences of the political party in power, which determine the feasibility of technology options and other viable alternatives in achieving the policy goals.

- Institutions are responsible for the monitoring, evaluation and verification of government actions.

- Politics is dynamic and is defined by power relations between actors

- Existing polities serve as formal and material frameworks that allows weaker parties to cope with asymmetrical relations

- Polities review how new policies are in accordance with the existing rules of the game while evaluating the resilience of the system.

- While the government may set the limits of what is politically acceptable through guard-rails that exclude intolerable impacts to both the issues involved and the instruments chosen to address these issues, the same government needs to adhere to these limits.

- The transition process and the transformed stage need to accommodate calls for re-negotiations through pre-defined measures.

The next step pertains to the enumeration and analysis of the deviations, where theoretical and empirical explanations to these deviations will be introduced. These explanations will focus on causal mechanisms.

Democratic structures conflate various conflicts, delaying the sustainable, low-carbon transformation process.

One major deviation of the Mexican transformation process from the ideal type is that Mexico's democratic structures actually conflate various conflicts. For example, with climate protection policies reduced to mere questions of 'governance,' the effective implementation of climate protection policies will be contingent on how deficiencies of governance are effectively addressed. While the climate agenda can be defined by the ideological preferences of the political party or administration in power, with the conflation of various conflicts, the feasibility of technology options to achieve low-carbon transformation is no longer defined 
by the ideological preferences of the ruling political actor vis-à-vis low-carbon transformation, but rather by its ideological preferences on governance. This delays the sustainable, low-carbon transformation process.

This deviation can be explained by how the state monopolizes the public sphere. Compared to the provision of the ideal type, which suggests that the competitive advantage of political actors in democratic countries is defined by how they can manage to align their political interests with public opinion, or how these political actors can shape public opinion, the political elite in Mexico is able to profit from unequal, old practices and traditions based on dependence, such as clientelism, corporatism, and patrimonialism, which further reinforces legitimacy gaps, as political actors have a high degree of structural autonomy from the society (see Olvera 1997). Furthermore, the concomitant absence of operative legal institutions as well as the limited public space for normative political discussions further contribute to the state's monopoly of the public sphere, which motivates the 'over-politicization' of specific issues (including climate protection and sustainable development) in order to maintain state control.

Mexico's capacity to host representative public discourse is yet to be developed in a way that is inclusive and that moves away from the center-periphery structure of decision-making (see Aguilera Portales \& Gonzáles Cruz 2010). The current lack of opportunity to participate and express interests in forums is seen to increase and further justify violence towards politicians, which further motivates politicians to defer consultations. Mexican civil society faces various difficulties inhibiting their full participation in decision-making (Aguilera Portales 2010; Aguilera Portales \& Sánchez Garcia 2010). Alberto Olvera (1997) argues that the unstable character of a civil society composed of social movements without, or with limited, operative civil, political, and social rights and capacities limit any type of transformation process. These difficulties are perceived to have roots in the colonial period, where a small but powerful elite was successful in politically, socially, and economically disenfranchising the majority of the population by completely insulating itself from societal influences. While local communities are usually able to influence local decisions, several decisions made in the capital city, especially those involving international partners including multinational companies, are often already finalized in closed-door meetings without prior consultation at the local level. These decisions often face resistance, further politicizing issues. This can be regarded as the result of Mexico's complex, segregated and decentralized policy processes, whereas the coordination and fusion of public and private resources are still controlled by the federal government, especially when these resources are provided by donors from abroad. Particularly when international projects follow a strict time schedule, the lengthy process of con- 
sultation at various levels will most likely motivate policy-makers to skip tedious consultations.

Relevant stakeholders, particularly in the civil society, are unable to participate in the consensus-building process, because they are unable to influence the definition of consensual knowledge.

The ideal type of democratic policy model denotes a highly educated and informed civil society that is capable of understanding and defining problems and their technical aspects, identifying relevant agendas, and assessing the effectiveness of proposed solutions. As Mexico needs to come up with a clear plan to implement its transition from fossil fuels to renewable energies through robust policies and regulations, the government needs to mobilize local partners, which include social groups, to enable rapid deployment of policies. For the civil society to be able to identify and assess the social and environmental impacts of the implementation of policies, it requires the opportunity to contribute to consensual knowledge.

In Mexico, a significant vacuum in the technical expertise of its civil society representatives is seen as a major hindrance to including them in technical consultations (Aguilera Portales 2011). Without a proper understanding of the technical issues involved, their potential participation in any type of knowledge diplomacy (see chapter 5) is merely "rhetorical" and is therefore not expected to yield constructive discussions and solutions, which further motivates the political elite to exclude them. In addition, the ideal type entails that all decisions made by policy-makers are happen after consultation with societal groups in a self-evident manner. Deviation from the conditions of this ideal type can be explained in various ways. One possible explanation is that organizing consultation processes is dependent on existing networks. As a network, stakeholders have already been identified and cooperation is self-evident. Similar to many countries in Latin America, advocacy by non-governmental organizations in Mexico is usually connoted as opposition to state actions, which are often seen as lacking transparency and political accountability (Aguilera Portales \& Gonzáles Cruz 2010). With this background, Mexican societal groups are distrustful of cooperation with perceived authoritarian state agencies (Franco et al. 2010; Natal et al. 2010; Martínez-Cárdenas et al. 2015). This manifests as the reality that social capital is yet to be strengthened in Mexico. High social capital means state agencies can be trusted to pursue the interests of society even when these interests contrast with their own personal interests. 
Mexican civic society initially mobilized the broader society in the $1980 \mathrm{~s}$ to form urban social movements, and continued in 1990s to demand transparent political processes and political accountability following the electoral fraud in 1988 (see Fox \& Hernandez 1992; Aguayo Quezada \& Parra Rosales 1997). This mobilization was highly repressed by the federal and state governments, as it was seen as a threat to the political stability of the country. From that point to the present, the attention and resources of Mexican civil society has been primarily directed towards good governance (see Feinberg et al. 2006). Environmental issues that affect various parts of society are more often addressed as merely a question of political governance, particularly regarding the political inclusion of marginalized sectors of society. Here arise various missed opportunities, both for Mexican civil society and policy-makers. For example, the resistance of indigenous communities to the wind farm project of Mareña Renovables in Oaxaca is merely seen as a political conflict, with the indigenous opposition not allowing any talks, taking the attention of the debate away from the concrete environmental and livelihood problems arising from the project (see McGovern 2014).

Another deviation of Mexico from the ideal type pertains to the lack of self-evident relationships between policy-makers and epistemic communities, between policy-makers and advocacy groups, and between epistemic communities and advocacy groups. The National Strategy refers to the potential role of civil society groups and of the research community. However, it is not clear whether all relevant civil society groups were involved in any form of the consultation process when drafting this national strategy or when writing the background paper through the World Bank. Low-carbon economy development in Mexico will affect all aspects of human life, from land use change to livelihood, from forms of housing to transportation. Therefore, the national strategy should also define consultation processes with both civil society groups and epistemic communities.

The history of Mexico 'disqualifies' presumed hosts or facilitators of public discourse

As identified by the ideal type, universities and other academic institutions can play a significant role in providing a 'public space' where various societal groups can meet and exchange perspectives. Universities and other academic institutions are often chosen as venues of public debate as they symbolize objectivity and neutrality. In several European countries, public discourse is often hosted by such institutions. In other countries like the Philippines and Thailand, the church 
often provides 'venues' or actively facilitates dialogues between conflict groups. Historically, however, both universities and the church are not seen as suitable and credible facilitators in Mexico. The Revolution of 1910, where the Catholic Church in Mexico served as one of the hallmark supporters of the dictatorship of Porfirio Diaz, reminds social movements that the Catholic Church is a force of the right and that it only pursues its own interest (see Quirk 1973). In the same manner, universities have traditionally played the role of (left) opposition to the government (see Lorey 1993). With this background, looking back at the ideal type diagram, the public consensus approach still needs to be developed in Mexico.

This case study on Mexico is not a comprehensive analysis of the transformation process of Mexico. Using the ideal type, relevant questions can be formulated that could be subjects of further studies.

\subsection{Case Study: The Agency of Transformation Process in China-State-Guided Transition Management}

China's sustainable, low-carbon transformation has profited from past decisions made by the Chinese leadership, whose primary interest of maintaining the political legitimacy of its authoritarian regime has proven to have produced favorable conditions for China's low-carbon transformation. China's reforms and drive to open up have catalyzed a series of transformations in their society, economy and politics (Haifeng 2014). Unlike in democratic regimes, where governments often think that they can rely on the electoral process alone for legitimacy, authoritarian regimes depend on other means of legitimacy. After decades of seeing climate protection as something that undermines its economic development, or that emissions are merely a matter of international diplomacy rather than environmental sustainability (see Aden \& Sinton 2006), China has begun to play a prominent role in reaching the Paris Agreement. With this shift in behavior, the Chinese leadership has finally acknowledged that by joining the global trend of low-carbon transition, it can further expand its political legitimacy (see Cao 2018).

Surprisingly, this change in China's behavior is made possible by its earlier decisions, which serve as necessary components of policy changes. For example, by changing its national development strategy in 2002, prioritizing economic efficiency between 1992-2002 by reforming its welfare policies, and by opting to prioritize economic efficiency while giving consideration to fairness (Li 2013), policies that aim to promote sustainable development and climate protection that 
were often perceived as undermining economic growth are now getting the attention of reformers. China's high economic growth was not translated into a 'trickle down' of wealth to a huge portion of the population, as income inequality has continuously increased, leading to popular unrest. The SARS crisis in 2003 further motivated the government and the urban Chinese population to expand its welfare system as the negative externalities of unaffordable healthcare became visible (Li 2013).

Additional concerns have emerged as the pace of China's economic growth, in terms of real growth of GDP, has slowed down since 2007 (from 14.2 percent in 2007, to 9.4 percent in 2009, to 7.9 percent in 2012, to 6.7 percent in 2016) (NBS 2017). In light of the 2007 financial crisis and the threat of economic recession in China, the Chinese leadership recognized the necessity of restructuring the economy to reduce dependency on exports and boost domestic demand. To achieve this, a whole range of policies have been designed and implemented that aim to support economic growth while at the same time producing benefits to social welfare (Li 2013). Massive investments were executed, including in the transport network and urban power supply. It can be argued that this massive investment in the transportation sector has subsequently promoted modes of transportation that are run by electricity. After almost ten years of investment and the upgrade of infrastructures, policies and decisions from that point on have tended to favor renewable energies, because renewables are, with the availability of appropriate infrastructures, more attractive than fossil fuels. The modernization of the urban power supply to major Chinese cities has defined a stable and promising domestic energy demand, which increasingly prefers renewable energies.

In addition, with the slowing of the GDP, the Chinese leadership has accepted the need of gradually defining economic growth with industrial quality and efficiency promotion to accelerate the adjustment of economic structures leading to the shift from a factor- and investment-driven economy into an innovation-driven one (He 2016). With huge investment and upgrades already having been conducted more than ten years ago, China is now determined to actively promote the transformation of its economic development pattern, its supply-side structural reform of the energy system, and its domestic consumption behavior to achieve a sustainable, low-carbon system while building and further expanding upon its core competitiveness. Moreover, the central government seeks to address the over-capacity practices of high-energy consuming industries (He 2016).

China is expected to overachieve the $\mathrm{CO}_{2}$ reduction goals in its NDC, as well as its own national targets. China's $\mathrm{CO}_{2}$ emissions may have peaked more than ten years ahead of its Paris Agreement commitment of hitting its peak $\mathrm{CO}_{2}$ emissions before 2030. Around 2020, the terminal energy consumption and $\mathrm{CO}_{2}$ 
emissions from the industrial sector are expected to peak. Nevertheless, as the following figure illustrates, its NDC is not ambitious enough to be consistent with holding warming to below $2{ }^{\circ} \mathrm{C}$, let alone limiting it to $1.5^{\circ} \mathrm{C}$ as required under the Paris Agreement, and is instead consistent with warming between $3{ }^{\circ} \mathrm{C}$ and $4{ }^{\circ} \mathrm{C}$. Furthermore, the absence of comparable commitments regarding other, non- $\mathrm{CO}_{2}$ gases could mean that China's total GHG emissions will continue to increase until at least 2030.

\subsubsection{A comparison of the Ideal Type and an Empirical Case Study of China-Causal Mechanisms through Congruence Methods and Process-Tracing}

China fits the primary condition of the ideal type of an authoritarian policy model. The Chinese regime is considered to be continually stable and robust. While democratic movements have gained significance in the country, these are generally limited to Hong Kong. The economic transition of China can be argued as evidence that a market-oriented economy can exist within the political parameters of an authoritarian regime by complementing market policies with social welfare reforms.

The following are the most relevant provisions of this ideal type in the context of transformation, where significant deviations in the Chinese case can be observed:

- The recruitment of new members of the political elite is structured and eidetic.

- The interaction between policy-makers and scientific communities often involves scientific and technocratic elites with long-standing relationships with the state.

- Issues are securitized, paving way to the "suspension" of some current rules and the adoption of new rules, which gradually leads to a "new normal", particularly in political agenda-setting.

- Because stable authoritarian regimes derive their (output) legitimacy primarily from their performance in achieving indicators of modernization, bureaucracies of authoritarian regimes will most likely play a very significant role in the planning and management of processes.

- Although authoritarian countries tend to be governed center-to-periphery and top-down, there is a predictability of institutional interactions (implying stability), as the character of historically dominant policies will define the policies taken in new areas. 
- Persuasion interaction between elites and other social actors in authoritarian policy pathways tend to occur through informal and non-public channels, which are effective in channeling resistance towards constructive and cooperative relationships.

- Because authoritarian regimes will most likely influence all aspects of the transformation process, outcomes will require cooperation between different levels of state authority.

As in the case study of Mexico, the next step refers to the enumeration and analysis of the deviations, where theoretical and empirical explanations of these deviations will be introduced and explained.

\subsubsection{The changing meaning of social connections in selecting the political elite in China}

Authoritarian regimes are often defined by the exclusiveness of important political positions. Eidetic recruitment of the political elite is a major characteristic of their bureaucracies (e.g., a military regime with military personnel holding positions). Selection to the elite is usually defined mainly by political loyalty. While this is, in principle, also the case in China, where only members of the Communist Party can hold government positions, recruitment to the political elite in China has developed further than this. The criteria of selection now instead cater to efficiency, while pursuing the inclusion of ethnic minorities into the political elite. There are additional factors, which transcend party membership, that determine one's recruitment. In the last three decades, the Chinese leadership has instilled rules and norms into its elite selection process, prioritizing qualification and efficiency through nascent institutional mechanisms (see Cheng \& Yiou 2017). Such mechanisms include the formal institutionalization of the inclusion of ethnic minority cadres among party-state elites through the Law of Ethnic Minority Autonomous Areas of the People's Republic of China. The Law stipulates that the top post in the local government in all ethnic minority autonomous areas (from the township level to the provincial level) should be held by a leader from the same ethnic minority background as the majority of citizens in that area (Cheng Li \& Yiou Zhang 2017).

The academic literature on the selection of China's political elite identifies 'Guanxi,' the network-based system of favor exchange, as the major principle that drives political, economic and social interactions (see Chen \& Chao 2004). Nevertheless, in addition to formal rules, there are informal rules, particularly when selecting candidates for top positions that intend to circumvent Guanxi. For example, in the six CCP Central Committees that have formed since the $13^{\text {th }}$ 
Party Congress in 1987, ethnic minorities have been represented in the committee (between 10 to 11 percent of the membership). In addition, the seven-member Politburo, the most powerful body in the Chinese government, is itself responsible for selecting new members (Shirk 2012). Due to the informal rules adhered to by Politburo members, social connections and personal ties will instead reduce the likelihood of being selected to the Politburo. For example, officials will be required to recuse themselves from evaluating candidates from their own regions or those who have connections to them, like college ties (see Fisman et al. 2017).

Reforms in governance and other structural changes have further supported the creation of a new political elite. The concept of 'elite dualism' has defined the Chinese system of governance. The division of labor between the CCP and the government in governance has led to two distinctive career paths. While candidates for elite positions in the CCP are screened for technical qualifications and political credentials, those candidates for government positions are screened more rigorously for their human capital. In addition, promotion in the government system is more dependent on efficiency compared with promotions in the CCP hierarchy (Xiaowei 2004). This elite dualism can be identified as conducive to any transformation process that requires technical expertise from its policy-makers.

The selection of the political elite in China can be seen as similar to best 'practices' in democratic countries that aim to address corruption and red tape. While it can also be interpreted that these provisions in China are designed for propaganda purposes, they also promote efficiency, as social connections are increasingly limited by both formal and informal practices. In general, this development is not only beneficial when ensuring the long-term political legitimacy of the regime, but this also supports the low-carbon transformation process, as new recruits coming from other networks can provide much needed out-of-thebox thinking. China's new political elite has now a more integrated and pragmatic understanding of politics, economics, social issues and technologies compared with its past leadership (see Khan 2013).

\subsubsection{Institutional Interactions through Partnerships- Urban Entrepreneurialism and Urban Clusters (Chengshiqun) in China}

Authoritarian regimes dominate institutional, functional and bargaining interactions simply through their 'omnipresence' within government agencies, playing a very significant role in the planning and implementation of policies at all levels of governance. Past reforms have moved China significantly further away from a strict center-to-periphery and top-down style of governance. Rather than being a monolithic system, China's governance of science, innovation, and environmental 
decision-making has been characterized by 'fragmented authoritarianism,' with protracted bargaining between bureaucracy units, including ministries, advisory bodies and top-level 'National Leading Groups' (see Heggelund 2004; Tyfield et al. 2015) as well as fragmentation between levels of government. Partnerships between multiple stakeholders are reinforced by local networks, for example, between state-owned and private companies. These networks have been mobilized to implement the government's climate protection goals. Such networks include the Alliance of Peaking Pioneer Cities that aim to hit the peak of their city emissions in advance of national targets (see Hale 2017).

Another example of structural changes that are now unfolding refers to how local governments have re-invented themselves and how they have sought partnerships with business companies to promote local development. However, this development in China can also be understood as a measure of 'regaining' competencies that were increasingly outsourced by the state following the opening of markets to international business actors. Some scholars such as Jonas and Ward (Harrison \& Hoyler 2014; see Jonas \& Ward 2016) have claimed that the formation of city-region governance is a deliberate process of scale building, which involves both state and non-state actors. In addition, the re-emergence of city-region governance can be understood as a direct reaction to globalization, as Neil Brenner's $(1999,2004)$ research on 'state spatiality' describes, where the rise of regional governance can be broadly understood as a process of 'state reterritorialization', and the specific form of the city-region as 'state spatial selectivity', which means that a specific scale has been chosen or built by the state.

In many areas, such as Kunshan, a small city around 60 kilometers west of Shanghai, the formation and transformation of urban entrepreneurialism has facilitated economic devolution, paving the way for such areas to break out of the institutional constraints of state socialism and innovatively promote further devolution formally and informally from the state towards a development zone and town governance (Shiuh-Shen \& Fulong 2011). Local and city governments started to transform themselves into market-friendly agents whose key goals are to form an alliance with more investors to promote local economic development. The functionality of city governments has changed from being mainly a social welfare deliverer to an economic development promoter. This change has further cemented the prioritization of economic efficiency at the grass-root levels.

Furthermore, as an indirect consequence of increased competition among cities, urban governance has become more cooperative, with other neighboring administrations under certain regional coordination by upper-level governments. The concept of urban clusters (chengshiqun) (Yao \& Zhu 1992) has been 
revived and included as part of the agenda of government policies, either to build stronger coalitions for regional competitiveness or to solve the over-concentration of growth in large central cities (Wu 2016). Particularly because of the limits of economies of scale, local governments have opted to share and combine resources to maximize benefits. Interestingly, the resurgence of urban clusters in China has been highlighted as an effective policy, as China has sought to solve environmental problems. For example, in an effort to find solutions to the problems of smog and population over-concentration, the Chinese leader Xi Jinping proposed, in 2014, a regional approach to the future development of Beijing in the capital's region (Jing-Jin-Ji), which led to further discussions about city-region governance (Wu 2016). In March 2015, the central government approved the outline of the Jing-Jin-Ji Collaborative Development Plan, which indicated that the notion of the urban cluster had become an official term in governance and had become popularized. In May 2016, the State Council approved the Yangtze River Delta Urban Cluster Development Plan (Wu 2016).

This newly evolved state-led coordinative and collaborative urban entrepreneurialism is regarded as one of the most important principles of China's market transition. While many villages still adhere to strong local corporatism, where family and kin members control local enterprises, this trend demonstrates an increase in the leasing of collectively-owned enterprises to private actors (see Heggelund 2009; Shiuh-Shen \& Fulong 2011). In addition, in contrast to the market logic, Chinese state-owned companies, which account for 80 percent of the stock market, tend to be more receptive to 'indigenous innovation' (zizhu chuangxin) mainly because of this state control (see Haifeng 2014).

As the central, regional, and local governments release new policy goals, such as moving up the value chain, state owned companies will tend to 'sacrifice' profit-making in order to internalize such policy goals. Furthermore, with the reform of elite selection (elite dualism) in place, government units are now technically able to effectively design and implement local development. With this new self-identification as an 'entrepreneurial state' (Mazzucato 2013), the Chinese central, regional, and local governments are not only driving research and development investment in strategic 'green' sectors, they are also constructing a market for innovation and building the skilled workforce required to serve emerging ideas of eco-innovation (see Tyfield et al. 2015) Furthermore, the asymmetrical transformation of the political and economic spheres in China involve the decentralization, in part, of economic decision-making, while the political system remains centralized and cadre promotion is based on the evaluation of the economic performance of their jurisdictions (Shiuh-Shen \& Fulong 2011). 


\subsection{Chapter Conclusion-Theory Testing and the Implications of Case Findings for Theory and Practice}

Of particular interest, in terms of the outcomes of the case studies, is how the gaps between theory and practice can be bridged. The case studies highlight how Mexico and China's deviation from the theoretical models of democratic and authoritarian policy models have captured interesting causalities that can be further conceptualized.

\subsubsection{Lessons for Theory}

The hypothesis that the successful implementation of sustainable, low-carbon policies is highly contingent on the capacity and autonomy of the State can be confirmed. However, as vindicated by the case studies, the terms 'capacity' and 'autonomy' require further concretization. State capacity, in the context of sustainable, low-carbon transformation, can be understood as how the State is able to accommodate different the perspectives of stakeholders affected by changes. As highlighted by Bruce Gilley (2012), China has the advantage of having relatively strong institutions that could manage the participatory process so as to ensure complementarities of top-down and bottom-up mechanisms (see Fraser et al. 2006; Stringer et al. 2007). Thus, as Gilley (2012) concludes, China had a potential advantage over more democratic regimes with weak states such as the Philippines and Thailand, as well as over more authoritarian regimes with weak states such as Myanmar (see Myint 2007).

As the Chinese leadership has linked inclusiveness with efficiency, formal and informal rules have been introduced and institutionalized to ensure representation in various decision-making processes. In contrast to China, Mexico seems to have more difficulties in engaging various stakeholders. In addition, autonomy, in the context of sustainable, low-carbon transformation, can pertain to how specific issues can be initially securitized to attract political attention and later on de-politicized to promote constructive collaboration. China is able to achieve a "new normal" in addressing emerging issues, because of structural reforms allowing the formal separation of political and non-political decision-making, where in some cases, non-political decision-making is outsourced to non-political actors for efficiency reasons. In Mexico, sustainable development and environmental issues are trapped in the political sphere, because of how the decision-making has been structured. 
Moreover, a comparison of the case studies on Mexico and China confirms that a democratic policy model does not guarantee inclusiveness in decision-making. Because of Mexico's focus on the electoral process as the main legitimizing source of governance, there is a sense that this question of legitimacy has already been resolved. Thus, there seems to be less motivation to ensure the efficiency of policies, as legitimacy has already been covered by electoral victories. In addition, as the Council on Hemispheric Affairs (2011) points out, failure in implementing robust, democratic foundations has led and has reinforced structural imbalances that promote clientelism in Mexican politics. In the context of sustainable, low-carbon transformation, Mexico's focus on the electoral process has unintentionally framed sustainability and climate mitigation as mere problems of governance, instead of ones of social cohesion, long-term and inclusive economic development, and of environmental integrity. By tracing the process of legitimization, the equifinality of paths becomes evident, as different paths can produce both similar and different outcomes and as similar paths can also produce both similar and different outcomes.

Nevertheless, China's focus on output legitimacy and the introduction of a "new normal" have both led to the kind of structural changes that are supposed to only be observed in democratic regimes. With economic efficiency combined with social welfare as the main principles, new formal and informal rules in policy-making in various spatial levels have been established. For example, family, hometown, and college ties \& connections are increasingly negatively affecting a person's selection to the Chinese political and economic elite. Therefore, elite recruitment has become more inclusive and fluid in China. Elite dualism and urban entrepreneurialism can be assessed as positively affecting sustainable, low-carbon transformation, because of wider participation in decision-making processes. While China cannot represent all existing authoritarian regimes, this case study demonstrates the normative traps of some theories (e.g., democratic peace) and how a case-to-case perspective can provide knowledge on the limitations of such theories.

In addition, while holistic approaches are needed as a basis for the comparison of cases which can be provided by "alternative settings" in order to generate useful knowledge, as the Ideal types suggest, additional subjects and additional ways of analyzing historical social processes for further research can allow a more integrated approach to problems and solutions. The introduced ideal type of transformation looks at the orchestration of various negotiation processes that are occurring at various levels within the system. The understanding of these different interdependencies in the various levels supports strategic planning in order to reduce transition costs and increase the political legitimacy of the outcome of the 
processes. Knowing that specific activities are aiming to come up with the agenda provides some time to prepare and manage conflicts that can be anticipated.

\subsubsection{Lessons for Practice}

The reasons why some climate protection measures are more successful in some countries than others cannot be fully explained, for example, by merely determining whether a country is democratic or authoritarian. It also depends on how "success" is defined. While China is often applauded because of its commitment to certain climate protection measures, it remains a question of whether it can still be considered as a success for climate protection when the motivations behind these decisions are not to protect the climate but, for instance, to combat air pollution. What happens when such goals have already been met before achieving long-term climate protection goals? Nevertheless, this question is only relevant when authoritarianism is understood as monolithic. For example, civil society groups and other stakeholders have more leverage over decision-making around environmentalism, climate change and innovation policies than in previous eras in China (Tyfield et al. 2015).

While governance structures have obvious and latent implications for societal consensus-building processes, consensus-building is dependent on the formal and material capacities of the relevant stakeholders to actually participate in the process. Effective management of transformation processes needs to effectively establish 'negotiative' mechanisms that allow the continuous revisiting of decisions that have been made in the past. The case study on Mexico's transformation process is merely a glimpse into the factors that are often neglected in the strategic planning of transformation to a low-carbon economy. Consensus-building is not self-perpetuating, especially not on countries with a government crisis related to the lack of transparency and accountability. Issues such as creating public space and empowering societal groups to be able to participate in orchestrated negotiation processes are often not adequately included or addressed in national strategies. As Raiza Pilatowsky Gruner (2016) argues, Mexico's lack of transparency and accountability at all levels of government will remain a major challenge and barrier to climate change national goals being enforced. This is reflected in a shortage of implementation and surveillance mechanisms and clear actions that will help to comply with the Paris Agreement pledges the country has made. With recent efforts of civil society groups to demand accountability and transparency from all levels of governance, climate policies can become 'collateral damage.' 
The emergence of a bottom-up, green public space is crucial to the sustainable, low-carbon transformation process. By developing the capacity of societal actors to express and pursue their interests, decisions that are made will most likely become more effective. Inclusivity is an investment, because the costs of transition will not only be shouldered by more actors, but the total costs will also be limited, as individual stakeholders will limit the negative externalities that they are producing for the others, because they will also be paying for them.

Open Access This chapter is licensed under the terms of the Creative Commons Attribution 4.0 International License (http://creativecommons.org/licenses/by/4.0/), which permits use, sharing, adaptation, distribution and reproduction in any medium or format, as long as you give appropriate credit to the original author(s) and the source, provide a link to the Creative Commons license and indicate if changes were made.

The images or other third party material in this chapter are included in the chapter's Creative Commons license, unless indicated otherwise in a credit line to the material. If material is not included in the chapter's Creative Commons license and your intended use is not permitted by statutory regulation or exceeds the permitted use, you will need to obtain permission directly from the copyright holder.

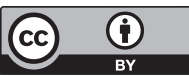

